Journal of Animal and Veterinary Advances 10 (2): 241-245, 2011

ISSN: $1680-5593$

(C) Medwell Journals, 2011

\title{
Derivation and Characteristics of ES-Like Cells in Chicken Fetal Ovarian
}

\author{
${ }^{1}$ Chuan-Sheng Zhang, ${ }^{2}$ Li-Ying Geng, ${ }^{3}$ Chun-Guang Yin, ${ }^{4}$ D.U. Li-Xin, \\ ${ }^{1}$ Zheng-Zhu Liu, ${ }^{1}$ Zhi-Xin Fu, ${ }^{1}$ Shen Ping, ${ }^{1}$ Chen Juan, ${ }^{1}$ Qing-Hui Jia and ${ }^{1}$ Xie-Rong Liu \\ ${ }^{1}$ Department of Animal Science, ${ }^{2}$ Department of Life Science, \\ Hebei Normal University of Science and Technology, 066600 Changli, China \\ ${ }^{3}$ Department of Life Sciences and Engineering, \\ Jining University, Shandong, 273155 Jining, China \\ ${ }^{4}$ National Center for Molecular Genetics and Breeding of Animal, \\ Institute of Animal Science, Chinese Academy of Agricultural Sciences, 100193 Beijing, China
}

\begin{abstract}
In the present study, the ES-like cells were derived from chicken fetal ovarian. These cells exhibit features similar to those of chicken EG cells such as typical bird nest morphology, strong reactivity toward periodic acid-Schiff and alkaline phosphatase staining. They could be maintained for more than a month on STO feeder in vitro, expressed the pluripotent markers such as stage specific embryonic antigen-1, stage-specific embryonic antigen-4, tumor rejection antigen-1-60 and tumor rejection antigen-1-81. Furthermore, the ES-like cells could form embryoid bodies and differentiate to several kinds of cells in vitro. Their easy accessibility makes these cells an attractive alternative to chicken ES cells for future functional and genomic studies and comparison with other stem cells.
\end{abstract}

Key words: Embryonic stem cells, fetal chicken ovarian, in vitro culture, genome, comparison, China

\section{INTRODUCTION}

Chicken Embryonic Stem Cells (cESC) have a great potential as tools for transgenic animal production and studies of regulation of differentiation genes. cESC currently have been derived from pre-primitive streak blastodermal cells and primordial germ cells under specific culture conditions. These cells exhibit features similar to those of mouse ES cells and present high capacities to differentiate in vitro into various cell types (Lavial and Pain, 2010).

However, several reports indicated that the long-term cultured cESC seemed lost the ability to colonize the germ line and no transgenic chicken were got through $\mathrm{cESC}$ heretofore which limits its application in transgenic research (Zhu et al., 2005; Van de Lavoir et al., 2006a). For these drawbacks of $\mathrm{cESC}$, researchers have focused on finding alternative sources of multipotent cells.

Recently, multipotent ES-like cells have been derived from mouse testis and ovarian (Kubota and Brinster, 2008; Zou et al., 2009). In avian, male germline stem cells have been isolated from chicken fetal and neonatal testis cells (Jung et al., 2007; Yu et al., 2010). Here, we show that ES- like cells can also be generated from fetal chicken ovarian under specific conditions. These cells could proliferate for more than a month, express a set of typical markers of ES cells and be induced to differentiate into Embryoid Bodies (EB) in vitro.

\section{MATERIALS AND METHODS}

Isolation and culture of chicken ovarian cells: Fertilized eggs of Hyline brown chicken were incubated at $38.2^{\circ} \mathrm{C}$ and $60 \%$ relative humidity for 18 days in a forced-air incubator (FT-KF8; Fangtong, Beijing, China). The left ovary was removed female embryos and then was dissociated in $0.25 \%$ trypsin at Room Temperature (RT) for $5 \mathrm{~min}$. After the inactivation of trypsin with DMEM containing $15 \% \mathrm{FBS}$, the cells were harvested by centrifugation.

For primary culture, cell suspension containing both gonocytes and somatic cells at a density of $1 \times 10^{5} /$ well was cultured in 24 well plates (Coming Inc., Corning, NY) with complete medium consisting of DMEM, $10 \%$ FBS, $1 \%$ nonessential amino acid, $1 \mathrm{mM}$ HEPES, $1 \mathrm{mM}$ sodium pyruvate, $2 \mathrm{mM}$ 1-glutamine, $5.5 \times 10^{-5} \mathrm{M} \beta$ mercaptoethanol $100 \mu \mathrm{g} \mathrm{mL}^{-1}$ of streptomycin, $100 \mathrm{IU}$ $\mathrm{mL}^{-1}$ of penicillin, $5 \mathrm{ng} \mathrm{mL}-1$ of SCF, $10 \mathrm{IU} \mathrm{mL}^{-1}$ of LIF,

Corresponding Author: Chuan-Sheng Zhang, Laboratory of Molecular Genetics and Animal Breeding, Department of Animal Science, Hebei Normal University of Science and Technology, 066600 Changli, China 
$40 \mathrm{ng} \mathrm{mL} \mathrm{m}^{-1} \mathrm{GDNF}$ and $10 \mathrm{ng} \mathrm{mL}^{-1} \mathrm{bFGF}$. The ES-like cells colonies were digested with $0.25 \%$ trypsin and transferred into another a 24 well tissue culture with feeder cells of STO treated with $10 \mathrm{mg} \mathrm{mL}^{-1}$ mitomycin-C (Roche, Switzerland) for culture at a ratio of 1:2-4. The medium was changed every 2-3 days. The ES-like cells colonies were passaged at an interval of 4-6 days on average. All cultures were maintained at $37^{\circ} \mathrm{C}$ in a humidified atmosphere of $5 \% \mathrm{CO}_{2}$.

\section{Characterization of ES-like cells derived from chicken ovarian}

Periodic acid-schiff and alkaline phosphates staining: The ES-like cells colonies were fixed with $4 \%$ buffered paraformaldehyde for $10 \mathrm{~min}$ and rinsed with PBS three times. The cells then were immersed in periodic acid solution for $5 \mathrm{~min}$ and were subsequently treated in Schiff solution for 5-10 min. All procedures were performed at RT. PAS stained cells were observed under an inverted microscope (Nikon, Japan).

For alkaline phosphatase staining, we used a 5bromo-4-chloro-3-indoyl phosphate/nitroblue tetrazoliu $\mathrm{m}$ alkaline phosphatase substrate kit (Boster, Wuhan, China) according to the in structions of the manufacturer. Colored colonies were scored using an inverted fluorescence microscope (Nikon, Japan).

Immunofluorescence analysis: Cultured ES-like cells at the third passage were fixed with cold $4 \%$ paraformaldehyde for $15 \mathrm{~min}$ at $4^{\circ} \mathrm{C}$. Reactions were performed with cold PBS-containing $1 \mathrm{mg} \mathrm{mL}^{-1} \mathrm{BSA}$ at $4^{\circ} \mathrm{C}$. The first diluted antibody (ES Cell Characterization Kit, Chemicon's Millipore, American) was added overnight. After washing, the second antibody FITClabeled (Beyotime, Haimen, China) was added for $1 \mathrm{~h}$ and the cells were rewashed and then observed using an inverted Nikon fluorescence microscope.

Development of embryoid bodies in vitro: Cells were digested with $0.25 \%$ trypsin for $1 \mathrm{~min}$ at $37^{\circ} \mathrm{C}$ and then gently broken into small clumps and cultured in suspension on dishes in Differentiation Medium (DM) containing 5\% FBS and without growth cytokines. The medium was changed every 2 day. After 8 days, the cells aggregated to form Embryoid Bodies (EB) and then the EB was plated onto gelatin-coated dishes and cultured to allow the expansion of different types of cells.

\section{RESULTS AND DISCUSSION}

Culture and characterization of chicken ovarian cells: Dissociated gonadal cells derived from 18 day incubated embryos contain gonocytes as well as somatic cells. The gonocytes were morphologically disguisable from somatic as they were much larger in the ovarian (Fig. 1a). After 2-3 days of culture under a specific medium supplemented with LIF, SCF, bFGF and GDNF, these cells formed flat focal colonies within (Fig. 1b).

These cells subsequently formed sharp-edged and compact nest colonies (Fig. 1c) that resembled chicken EG cells (Fig. 1d) at about 7 day. These colonies could be further subcultured under specific conditions on gelatincoated dishes with STO layer for at least 4 weeks for 5 passages. These ES-like colonies were stained red by PAS staining (Fig. 1e,f) and displayed strong alkaline phosphatase activity (Fig. 1g). The morphology of ovarian-derived ES-like cells had a large nucleus and a relatively small amount of cytoplasm (Fig. 1h).

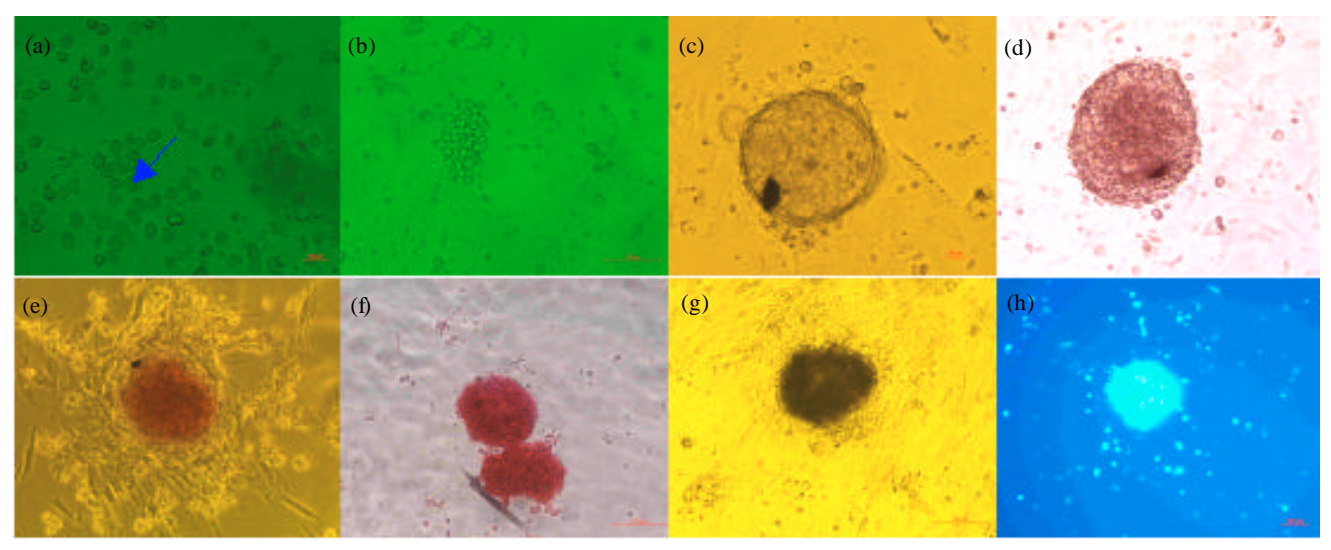

Fig. 1: Derivation and characteristics of ES-like cells obtained from chicken fetal ovarian; (a) chicken ovarian gonocytes $\times 300$, arrows indicate ovarian gonocyte, (b) chicken ovarian gonocytes cultured 2-3 day, formation of small clusters $\times 50$, (c) the primary ES-Like cells colony $\times 400$, (d) chicken EG cells colony $\times 400$, (e) PAS staining ESlike cells $\times 250$, (f) PAS staining the 3 passages ES-like cells $\times 250$, (g) AKP staining $\times 250$ and (h) DAPI staining $\times 250$ 


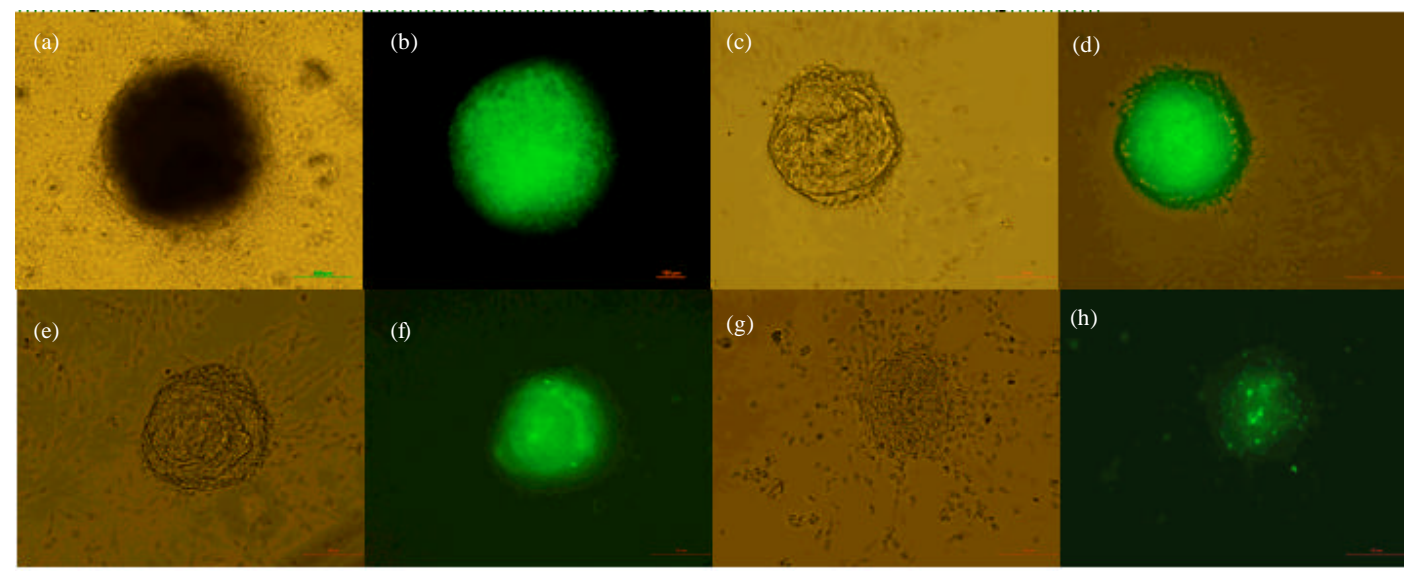

Fig. 2: Especial immunohistochemical analysis of ovarian-derived ES-like cells on feeder layer of STO; $(a, b)$ phase contrast and SSEA-1 detection $\times 250$, (c, d) phase contrast and SSEA-4 detection $\times 250$, (e, f) phase contrast and TRA-1-60 detection $\times 250$ and $(\mathrm{g}, \mathrm{h})$ phase contrast and TRA-A- 81 detection $\times 250$

ES-like cells were successful obtained from chicken fetal ovarian in this study and cultured under the medium that resembled the medium used for chicken PGCs culture (Park et al., 2003), except for the supplemented GDNF. Recent study proved that GDNF was essential for germline stem cells self-renewal and proliferation in mouse (Zou et al., 2009). LIF are known to promote the maintenance or proliferation of chicken ES without inducing differentiation in vitro (Pain et al., 1996). SCF was required for cell survival and proliferation and $\mathrm{bFGF}$ was absolutely required for the long-term culture of chicken PGCs led to the derivation of large colonies of EG cells (Park et al., 2003).

Marker expression of ovarian-derived ES-like cells: Cells maintained in ovarian-derived ES-like cells cultures were characterized using a set of (SSEA-1, SSEA-4, TRA-1-60 and TRA-1-81) antibodies known to identify EG and ES cells (Wang et al., 2010). The subcultured ES-like cells were fixed and analyzed for expression of epitopes known to be specific of ES and EG cell.

The epitopes recognized by the monoclonal antibodies SSEA-1 which are expressed by nondifferentiated ES and EG cells in chicken (Pain et al., 1996; Wang et al., 2010) were also expressed on colonies in ovarian-derived ES-like cells (Fig. 2b). Another antibody, SSEA-4 which recognizes a specific epitope on EG cells in chicken (Wang et al., 2010) also labeled ovarianderived ES-like cells (Fig. 2d). The TRA-1-60 and TRA-1 81 antibodies recognize epitopes specifically on both EG and ES in human (Henderson et al., 2002). We observed that these two antibodies also label ovarian-derived ES-like cells (Fig. 2f, h). As such, these ovarian-derived ES-like cells are different from human ES cells but similar to chicken EG.

Recent study proved that ovarian gonocytes obtained from 20 days incubated embryo without culture exhibit ability to migrate to the germinal ridges after transfer into the bloodstream of recipient embryos, enter the gonads and contribute to the germline lineage of chimeras embryos (Naito et al., 2007) which means some of ovarian gonocytes may share some phenotypic and functional characteristics with $\mathrm{PGCs}$ in chicken. Considering that chicken $\mathrm{PGC}$ maintain their restriction to the germ line (Van de Lavoir et al., 2006a) whereas chicken EG and ES cells contribute substantially to somatic tissues but not to the germ line (Van de Lavoir et al., 2006b). Therefore, more research is needed to confirm whether the established cells have a germ line competent.

Differentiation in vitro: Upon exposure to in vitro directed differentiation conditions, ES-like cells after 3 passages could form EB with a heterogeneous morphology under differentiation medium culture for about 8 day (Fig. 3a). These EB-like structures could be maintained in these conditions for $>10$ days. When transferred onto tissue-culture dishes, these EB-like structures attached and spontaneously differentiated into several kinds of cells such as fibroblast-like cells, neuronal cells as shown in Fig. 3b within a few days. Therefore, these ES-like cells were capable of differentiation in vitro. 


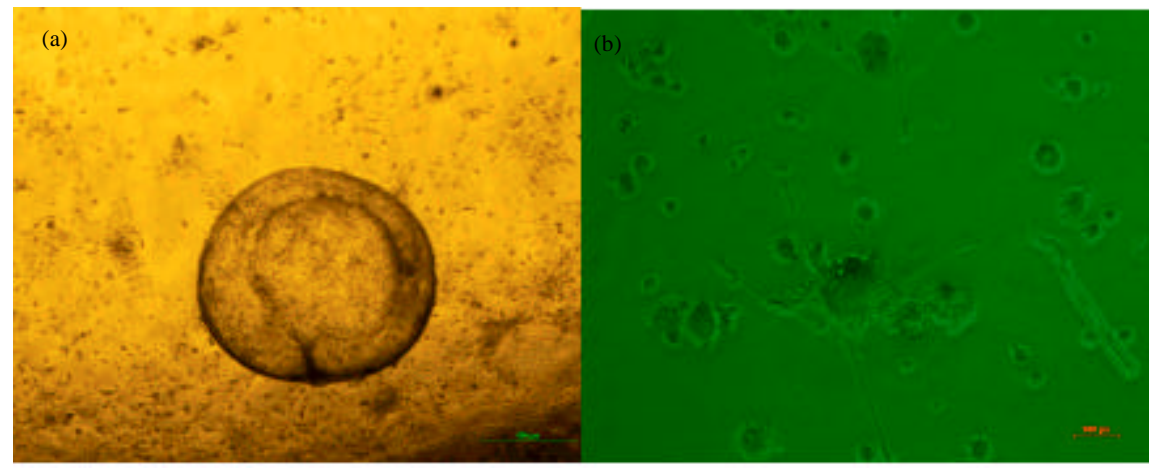

Fig. 3: Morphology of differentiated cells and Embryoid Bodies (EB) induced by chicken ES-like cells; (a) Embryoid bodies formed in suspension after 8 day of culture $\times 100$ and (b) The outgrowth of the EB contained cells with a typical neuronal morph $3 \log \times 250$

(b)

\section{CONCLUSION}

In this study, ES-like cells were isolated and characterized from fetal chicken ovarian. These cells exhibit a morphology and epitope profiles that are similar to those of chicken EG cells after a short term in culture. Considering the results of immunostaining with germ specific markers and spontaneous differentiation, we designated these colonies as ES-like cells.

Further study is necessary to determine the most efficient method to generate ES-like cells from chicken fetal ovarian. This will open the way to carrying out detailed research on ovarian-derived ES-like cells, possibly leading to applications important for the chicken industry like the production of transgenic animals by transfection of ES-like cells.

\section{ACKNOWLEDGEMENTS}

This research was supported by Natural Science Foundation of Hebei Province (No. C2008001308) and National Science Foundation for Youths (No. 31001003) and Key Projects in the National Science and Technology Pillar Program during the 15 Plan Periods ( No.2008BADB2B04-8-4).

\section{REFERENCES}

Henderson, J.K., J.S. Draper, H.S. Baillie, S. Fishel, J.A. Thomson, H. Moore and P.W. Andrews, 2002. Preimplantation human embryos and embryonic stem cells show comparable expression of stage-specific embryonic antigens. Stem Cells, 20: $329-337$.
Jung, J.G., Y.M. Lee, T.S. Park, S.H. Park, J.M. Lim and J.Y. Han, 2007. Identification, culture and characterization of germline stem cell-like cells in chicken testes. Biol. Reprod., 76: 173-182.

Kubota, H. and R.L. Brinster, 2008. Culture of rodent spermatogonial stem cells, male germline stem cells of the postnatal animal. Methods Cell Biol., 86: $59-84$.

Lavial, F. and B. Pain, 2010. Chicken embryonic stem cells as a non-mammalian embryonic stem cell model. Dev. Growth Differentiation, 52: 101-114.

Naito, M., T. Minematsu, T. Harumi and T. Kuwana, 2007. Testicular and ovarian gonocytes from 20-day incubated chicken embryos contribute to germline lineage after transfer into bloodstream of recipient embryos. Reproduction, 134: 577-584.

Pain B., M.E. Clark, M. Shen, H. Nakazawa, M. Sakurai, J. Samarut and R.J. Etches, 1996. Long-term in vitro culture and characterization of avian embryonic stem cells with multiple morphogenetic potentialities. Development, 122: 2339-2348.

Park, T.S., Y.H. Hong, S.C. Kwon, J.M. Lim and J.Y. Han, 2003. Birth of germline chimeras by transfer of chicken Embryonic Germ (EG) cells into recipient embryos. Mol. Reprod. Dev., 65: 389-395.

Van de Lavoir, M.C., C. Mather-Love, P. Leighton, J.H. Diamond and B.S. Heyer et al., 2006a. High-grade transgenic somatic chimeras from chicken embryonic stem cells. Mechanisms Dev., 123: 31-41.

Van de Lavoir, M.C., J.H. Diamond, P.A. Leighton, C. Mather-Love and B.S. Heyer et al., 2006b. Germline transmission of genetically modified primordial germ cells. Nature, 8: 766-769. 
Wang, Y., L. Hou, C. Li, W. Guan and L. Chen et al., 2010. Isolation, culture and biological characteristics of primordial germ cells from Beijing fatty chicken. J. Reprod. Dev., 56: 303-308.

Yu, F., L.J. Ding, G.B. Sun, P.X. Sun, X.H. He, L.G. Ni and B.C. Li, 2010. Transgenic sperm produced by electrotransfection and allogeneic transplantation of chicken fetal spermatogonial stem cells. Mol. Reprod. Dev., 77: 340-347.
Zhu, L., M.C. van de Lavoir, J. Albanese, D.O. Beenhouwer and P.M. Cardarelli et al., 2005. Production of human monoclonal antibody in eggs of chimeric chickens. Nat. Biotechnol., 23: 1159-1169.

Zou, K., Z. Yuan, Z. Yang, H. Luo and K. Sun et al., 2009. Production of offspring from a germline stem cell line derived from neonatal ovaries. Nat. Cell Biol., 11: 631-636. 